\title{
La libertad en el idealismo trascendental de Fichte según la lectura de Cornelio Fabro
}

\author{
Cristian Eduardo Benavides \\ Universidad Nacional de Cuyo - CONICET \\ Mendoza - Argentina \\ cristianeduardobenavides@yahoo.com.ar
}

\section{Resumen:}

El presente trabajo tiene el propósito de examinar, siguiendo puntualmente la lectura y comentarios del filósofo italiano Cornelio Fabro, el desarrollo del idealismo trascendental fichteano en lo que concierne de forma particular a su noción de libertad. Los tópicos que se estudiarán tendrán un marco bien definido, a saber: se intentará mostrar primeramente la interpretación fabriana de Fichte; en segundo lugar, se dará cuenta del juicio de Fabro sobre algunos puntos concretos del idealismo fichteano; y finalmente, aunque de modo más bien indirecto y transversal, se señalará la influencia de Fichte en la propia reflexión de Fabro sobre la noción de libertad.

Palabras Clave: Yo, Libertad, Idealismo, Trascendental, Absoluto

\begin{abstract}
:
The present paper aims to examine the development of Fichte transcendental idealism, studying particularly his notion of freedom, following the reading and comments of Fichte made by the Italian philosopher Cornelio Fabro. Issues to be discussed have a defined framework: first, it will be tried to shown Fabro's interpretation of Fichte; second, it will be gave account of Fabro's judgment about some particular points of Fichte idealism; and finally -but indirectly- it will be shown the influence of Fichte over Fabro himself notion of freedom.
\end{abstract}




\section{Keywords:}

Self, Freedom, Idealism, Transcendental, Absolute

\section{Introducción}

La libertad es el tema dominante de la filosofía moderna, la problemática central de aquél movimiento especulativo que nace con el cogito cartesiano y que encuentra su culminación, al menos así lo refiere comúnmente la historiografía, en el idealismo hegeliano. Entre uno y otro pensador, numerosos filósofos exponen un discurso esencialmente racional que se impone como meta propia el significado, o mejor, el fundamento (Grund) y fundamentación misma del concepto de libertad.

Autores de notable influencia e importancia para la historia de la filosofía y de la cultura universal tienen su lugar en este importante y revolucionario período histórico. Kant se convierte, sin lugar a dudas, en el punto de inflexión de una etapa que pasa, a partir de su pensamiento crítico y a través de la instauración del trascendental del que da origen, a la comprensión de la realidad como totalidad, esto es, como un todo (Ganze) o bien como un sistema de la unidad, de lo Uno.

El pensamiento de Fichte tiene, al respecto, un lugar preponderante. Su reflexión filosófica da comienzo al idealismo metafísico alemán, el cual en cierto modo continúa y profundiza el pensamiento kantiano en pos de su resolución, esto es, en pos de una superación cabal de todo residuo dicotómico y dual. Dicha tarea es llevada a cabo mediante una tesis radical: la afirmación del Yo Absoluto.

El presente trabajo tiene el propósito de examinar, siguiendo puntualmente la lectura y comentarios del filósofo italiano Cornelio Fabro, el desarrollo del idealismo trascendental fichteano en lo que concierne de forma particular a su noción de libertad.

La obra intelectual de Fabro comprende especialmente los trabajos exegéticos de índole metafísica sobre el filósofo medieval Tomás de Aquino. ${ }^{1}$ No obstante, son también

\footnotetext{
${ }^{1}$ Entre otros libros referidos al pensamiento del doctor medieval, pueden mencionarse los siguientes: C. FABRo, La nozione metafisica di partecipazione secondo San Tommaso d'Aquino. Vita e Pensiero, Milano, 1939; Breve introduzione al tomismo, Desclée, Roma, 1960; Partecipazione e causalità secondo San 
numerosos los libros, artículos y cursos académicos universitarios que dedica total o parcialmente al pensamiento moderno y contemporáneo. ${ }^{2}$

Pese a que ya algunos especialistas han señalado la importancia de los autores idealistas - y de Fichte singularmente - en la propia concepción de Fabro sobre la noción de libertad, dichos estudios son breves y no se detienen de forma detallada o pormenorizada en el asunto. ${ }^{3}$ En estas páginas se intentará precisamente aportar un conocimiento más global, analítico y profundo de esta temática.

Es necesario aclarar antes de comenzar con el núcleo del escrito, que no se presentará la compleja trama del sistema fichteano en el conjunto de sus variados y laberínticos aspectos; dicha labor excedería por mucho los límites aquí asignados. Solo se examinarán pues los puntos que Fabro trata del mismo, teniendo particularmente en cuenta los supuestos metafísicos con los que aborda esta investigación. En este sentido cabe brevemente señalar que la interpretación fabriana de Fichte lejos está de ser ortodoxa o convencional, pues no es extraño encontrar en el fondo de algunas afirmaciones y confrontaciones su propio razonamiento sobre el tema en debate.

Por todo, los tópicos que se estudiarán tendrán un marco bien definido, a saber: intentarán mostrar por un lado la interpretación fabriana de Fichte; por otro lado darán cuenta del juicio de Fabro en algunos puntos concretos del idealismo fichteano; y finalmente, aunque de modo más bien indirecto y transversal, señalarán la influencia de Fichte en la propia reflexión de Fabro sobre la noción de libertad.

Tommaso d'Aquino, S.E.I., Torino, 1960; Esegesi tomistica, Pontificia Università Lateranense, Roma, 1969; Tomismo e pensiero moderno, Pontificia Università Lateranense, Roma, 1969; Introduzione a S. Tommaso. La metafisica tomista e il pensiero moderno, Ares, Milano, 1983.

${ }^{2} \mathrm{Al}$ respecto pueden destacarse las siguientes obras: C. FABRO, Introduzione all'esistenzialismo, Vita e Pensiero, Milano, 1943; Problemi dell'esistenzialismo, A.V.E., Roma, 1945; L'Assoluto nell'esistenzialismo, Catania, Milano, 1953; Dall'essere all'esistente, Morcelliana, Brescia, 1957; Studi kierkegaardiani, Morcelliana, Brescia, 1957; Introduzione all'ateismo moderno, Studium, Roma, 1964; La preghiera nel pensiero moderno, Ed. di Storia e Letteratura, Roma, 1979; Riflessioni sulla Libertà, Maggioli, Rimini, 1983. Debe tenerse en cuenta que la obra de Fabro es verdaderamente cuantiosa: escribió cerca de 40 libros, 60 cuadernillos universitarios y casi 900 artículos. Además tradujo diferentes obras del alemán y del danés al italiano y colaboró en repetidas ocasiones en diccionarios y enciclopedias especializadas de todo el mundo.

${ }^{3}$ Uno de los autores que ha señalado este asunto, y quizá con mayor detenimiento que el resto de los estudiosos de Fabro, es Christian Ferraro, quien en el capítulo 2 de su tesis doctoral examina la interpretación fabriana de la libertad en el idealismo alemán, dedicando un breve apartado a la lectura de Fichte. Cf. . Christian FERRARO, Creatividad participada. La interpretación de la libertad radical según el "tomismo esencial” de Cornelio Fabro, Pontificia Università Lateranense, Roma, 2009, 65-71. 


\section{La concepción fichteana del Yo como unidad analítica}

Según el parecer de Cornelio Fabro, Fichte ha dedicado al problema de la libertad uno de los máximos empeños teoréticos de la historia del pensamiento: ${ }^{4}$

Tal vez ningún filósofo moderno, y tal vez en el arco del pensamiento de todos los tiempos, ha quedado tan cautivado por el problema de la libertad como Fichte: la excepcional tensión de su reflexión y de sus polémicas tienen aquí el centro, el objeto y el fin. ${ }^{5}$

Pues bien, la obra fichteana tiene en su plataforma filosófica fundamentalmente a dos autores: Spinoza y Kant. Del primero asume el principio de la unidad del ser. ${ }^{6}$ Del segundo asume el principio de la creatividad de la conciencia, esto es, el principio de libertad como esencia y fundamento de la vida del espíritu. ${ }^{7}$ La síntesis de su idealismo tiene, en este sentido, el propósito de hacer avanzar a la filosofía desde la esfera del Verstand, que domina particularmente en Kant, a la esfera de la Vernunft. ${ }^{8}$

La Wissenschaftslehre fichteana busca superar el sustancialismo estático de Spinoza mediante la profundización de la instancia crítica kantiana. ${ }^{9}$ Esta labor tiene, en opinión del filósofo italiano, tres notas principales. Primero, «la asunción del Yo puro kantiano a Absoluto, es decir, la sustitución o transposición de la substancia en el Ich denke überhaupt». Segundo, «la desvinculación del denken kantiano de la referencia a la cosa en sí». Tercero, «la transformación del denken kantiano en la espontaneidad pura, en el acto

\footnotetext{
${ }^{4}$ «E proprio Fichte, ch'è forse il massimo analista della libertà di tutti i tempi...» (C. FABRO, "Breve discorso sulla libertà. Annotazioni su Fichte", en Rivista di filosofia neoscolastica, LXX, 1-2, 1978, 268).

5 «Forse nessun filosofo moderno, e forse nell'arco del pensiero di tutti i tempi, è stato così avvinto dal problema della libertà come Fichte: la tensione eccezionale della sua riflessioni e delle sue polemiche hanno qui il centro, l'oggetto e lo scopo» (C. FABRO, "Dialettica della libertà e autonomia della ragione in Fichte", en Riflessioni sulla libertà, 2 ed., Edivi, Segni, 2004, 127). Los textos de Fabro que se exponen en el cuerpo del escrito son todos de propia traducción, a no ser que se indique lo contrario.

${ }^{6}$ «En cuanto a Spinoza, Fiche observa que su sistema admite la conciencia empírica solamente y niega la conciencia absoluta -en la sustancia o Divinidad-. Fichte encuentra que tal pasaje es ilógico: pero acepta la doctrina espinozista [sic] en su afirmación de la unidad del ser» (C. FABRO, La dialéctica de Hegel, Columba, tr. Juan R. Courrèges, Buenos Aires, 1969, 41).

${ }^{7}$ Cf. C. FABRO, "Dialettica della libertà..., 128.

${ }^{8}$ Cf. C. FABRO, "La trascendentalità nella dialettica hegeliana", en Tempo e storicità dell'uomo, Gregoriana, Padova, 1971, 19.

${ }^{9}$ «La Wissenschaftslehre è la sintesi unificata in atto, portata avanti da Fichte per tutta la sua vita, dell'istanza realizzata separatamente da Kant nelle tre Critiche: una sintesi intrinseca di approfondimento» (C. FABRO, "Dialettica della libertà..., 128).
} 
(Tat) en sí». ${ }^{10}$ En realidad estos tres puntos pueden reducirse a uno solo, a saber, el pasaje del Yo funcional al Yo constitutivo, conforme con una especie de spinozismo superior que presenta al Yo kantiano más allá de todo límite tanto práctico cuanto especulativo.

El idealismo de Fichte se desarrolla particularmente en torno de la doctrina kantiana de la apercepción trascendental. Según Kant, la apercepción era la unidad sintética de todas las leyes del pensamiento, el fundamento de todas las categorías. El Ich denke era aquello que acompañaba todas las representaciones, ${ }^{11}$ la unidad que se realizaba mediante la conexión de lo múltiple de las intuiciones. ${ }^{12}$

Fichte, al igual que Kant, opina que la apercepción trascendental es el fundamento de todas las representaciones. Sin embargo, no concibe su unidad de forma sintética sino analítica. ${ }^{13}$ El Yo no puede ni debe considerarse mediante la conexión de lo múltiple de las representaciones, sino que más bien lo múltiple de las representaciones debe considerarse mediante la destrucción, difusión y división del uno sobre un múltiple mediante la forma de un devenir. ${ }^{14}$

El cambio de método de Fichte, explica Fabro, atiende particularmente a la unidad sustancial del acto espiritual, y en consecuencia, a la fundamental identidad de teoría y praxis. En este sentido se debe advertir que para el idealismo trascendental el Yo deja de ser entendido al modo kantiano como el simple acompañante de las representaciones, para pasar a ser concebido como la actividad primera e incondicionada del Sujeto Absoluto. ${ }^{15}$ En

${ }^{10}$ El texto del filósofo italiano dice así: «Il significato poi 'sistematico' di questa critica è anzitutto nell'assunzione dell'Io puro kantiano ad Assoluto ossia nella sostituzione o trasposizione della sostanza nello Ich denke überhaupt; poi, nello svincolamento del denken kantiano dal riferimento alla cosa in sé; infine nella trasformazione del denken kantiano nella spontaneità pura, nell'atto (Tat) in sé» (C. FABRO, Introduzione all'ateismo moderno, 2 ed., Studium, Roma, 1969, 578).

11 «Das: Ich denke, muß alle meine Vorstellungen begleiten können» (I. KANT, Kritik der reinen Vernunft, § 16, B 132, Kants Werke, III, Walter de Gruyter \& Co, Berlín, 1968, 108.

${ }^{12}$ Cf. I. KANT, Kritik der reinen Vernunft..., § 16, B 132, 108.

${ }^{13}$ La polémica de Fichte contra Kant puede verse en el curso: J. G. FICHTE, Ueber dar Verhältnis der Logik zur Philosophie oder transcendentale Logik, VIII Vortrag, Medicus VI, 195 ss.

${ }^{14}$ Cf. C. FABRO, "Libertad y persona en Santo Tomás”, en Gladius, II, 1, 1986, 8. El artículo fue publicado originalmente en castellano.

${ }^{15}$ El Yo es absoluta actividad, el primer principio originario que pone a sí mismo su propio ser. Al respecto Fichte presenta las siguientes deducciones trascendentales: «Das Ich ist für das Ich [...]. Ich bin nur für Mich; aber für Mich bin ich notwendig (indem ich sage für Mich, setze ich schon mein Sein). Sich selbst setzen, und Sein, sind, vom Ich gebraucht, völlig gleich. [...]. Ich bin schlechthin, weil ich bin. Ferner, das sich setzende Ich, und das seiende Ich sind wöllig gleich, Ein und ebendasselbe. [...]. Ich bin schlechthin, was ich bin. Der unmittelbare Audruck der jetzt entwickelten Tathandlung wäre folgende Formel: Ich bin schlechthin, d. i. ich bin schlechthin, weil ich bin schlechthin; und bin schlechthin, was ich bin; beides für das Ich. [...]. Das Ich 
otras palabras, el Yo fichteano deja de mostrarse como una simple presencia psicológica o fenomenológica, para revelarse como actividad óntica-ontológica que se constituye metafísicamente, esto es, como afirmación del Absoluto. ${ }^{16}$

La identidad de teoría y praxis del idealismo fichteano tiene de base el descubrimiento kantiano de la libertad trascendental. Para Kant, en efecto, la libertad trascendental era concebida como la síntesis en general de la sensibilidad (Sinnlichkeit), el entendimiento (Verstand), y la razón (Vernunft). Esta libertad, en tanto espontaneidad productiva, se expandía en la esfera teorética como función creativa de los juicios sintéticos a priori, y en la esfera práctica como forma de actividad del imperativo categórico. ${ }^{17}$

El filósofo italiano observa que esta noción crítica de libertad en cierto modo ya operaba la unificación de pensar y querer que posteriormente sistematizara Fichte. Pues si bien para Kant todo acto de conocer estaba ligado a la materia del fenómeno (Erscheinung), en su interior era una realidad que se trascendía a sí misma, esto es, era una realidad que se comprendía como actividad creativa.

No obstante lo desarrollado, en el pensamiento kantiano la identidad de teoría y praxis estaba todavía frenada por la posición del noúmeno. Fichte se propone justamente superar esta dualidad mediante la profundización de la libertad originaria, esto es, mediante la identificación de la actividad espiritual con la libertad.

Mientras que para Kant el noúmeno era una especie de cualidad oculta de un mundo inteligible no susceptible de verdadero conocimiento, Fichte, en cambio, sostiene que la cosa en sí (Ding an sich) es lo máximamente conocido y cognoscible, por tratarse precisamente de la actividad originaria del Yo queriente. ${ }^{18}$ En contraposición con la dogmática kantiana que reza: «el principio de explicación de la experiencia debe encontrarse fuera de la experiencia», ${ }^{19}$ el idealismo de Fichte afirma el querer inmediato del Yo como fundamento de la realidad nouménica.

setzt ursprünglich schlechthin sein eignes Sein» (J. G. FICHTE, Grundlage der gesamten Wissenschaftslehre, Medicus, I, 286 ss) Cursiva del autor.

${ }^{16}$ Cf. C. FABro, "Ateismo e Cristianesimo come momenti risolutivi del pensiero moderno", en Il mondo di domani, Abete, Roma, 1964, 194.

${ }^{17}$ Cf. C. FABRO, "Dialettica della libertà..., 130.

${ }^{18}$ Cf. C. FABRO, La dialéctica de Hegel..., 41-42.

${ }^{19}$ Para Fichte la realidad nouménica es una quimera propia del pensamiento dogmático: «Das Prinzip des Dogmatikers, das Ding an sich, ist nichts, und hat, wie der Verteidiger desselben selbst zugeben muß, keine 
Las distinciones del pensamiento crítico como aquellas de mundo sensible y mundo inteligible, fenómeno y noúmeno, adquieren en la doctrina de Fichte un significado meramente formal. Los opuestos tienen en realidad su raíz y fuente común en el Yo puro, identidad de conciencia y autoconciencia, ser y pensamiento, voluntad e inteligencia. ${ }^{20}$

\section{El saber absoluto y el primado de la voluntad}

Según los estudios de Fabro, la obra de Fichte retoma el dualismo de extensión y pensamiento de Spinoza y lo supera introduciendo una dualidad aun más profunda, a saber, la dualidad de ser y libertad. Ambas nociones tienen por momento crucial la convergencia y unificación en el saber absoluto (absolutes Wissen). Ser y libertad, contenido y autogénesis, devienen ser absoluto y libertad absoluta. Fichte habla de esta manera de la absoluta libertad del saber (absolute Freiheit des Wissens).

El filósofo italiano analiza con detenimiento la dialéctica fichteana de saber y libertad, siguiendo muy de cerca los textos del autor. Aquí sólo se aludirán sus citas y comentarios, en orden a una comprensión general de los rasgos más importantes de su exposición. $^{21}$

Pues bien, la dialéctica de saber y libertad que examina Fabro tiene cuatro momentos principales. ${ }^{22}$ En primer lugar Fichte afirma que no hay un saber absoluto e inmediato sino aquél que procede de la libertad. La libertad es pues y solamente el primer objeto inmediato de un saber. Este saber se refiere a la autoconciencia, es decir, es el saber como autorreflexión del Yo.

En segundo lugar Fichte declara que no hay libertad inmediata y absoluta sino en y para un saber. Dicha libertad no tiene otro fundamento de su determinación más que sí

Realität, außer diejenige, die es dadurch erhalten soll, daß nur aus ihm die Erfahrung sich erklären lasse» (J. G. FICHTE, Erste Einteilung in die Wissenschaftslehre, § 4,).

20 «Tutto in Fichte rimanda alla nuova concezione dell'Io con la quale egli intende di superare la frattura kantiana fra mondo intelligibile e mondo sensibile. Si può riconoscere pertanto che il concetto moderno di coscienza come attività originaria cioè fondante, ossia come "posizione di sé" nel portarsi all'altro, pertanto come identità di coscienza e autocoscienza e quindi di essere e pensare come di pensare e volere ed infine come diremo- di progettare e volere... è stato portato al suo termine senza remore» (C. FABRO, "Dialettica della libertà..., 132.).

${ }^{21}$ Se sigue entre líneas el artículo: C. FABRO, "Breve discorso sulla libertà..., 270-273.

${ }^{22}$ Cf. J. G. FiCHTE, Darstellung der Wissenschaftslehre aus dem Jahre 1801, § 15-19. 
misma. La libertad entonces se relaciona al saber como su fin y término. Así resulta que en el ser inmediato de la experiencia los opuestos se excluyen; mientras que en el saber, empero, los opuestos se recogen en su distinción y sucesión.

En tercer lugar Fichte afirma que saber y libertad están inseparablemente unidas, son una sola cosa (Eins). Si bien en la esfera del ser inmediato se presupone la diversidad y multiplicidad, la dualidad de ser y libertad, de mundo y sujeto; en verdad ambas nociones tienen su realidad en la unidad y unificación del saber absoluto.

En cuarto y último lugar Fichte concluye que el saber absoluto es el objeto propio de la intuición intelectual (Intellektuelle Anschauung).

En este desarrollo trascendental del saber, sin embargo, Fichte no puede dejar de reconocer una cierta duplicidad (Duplizität) entre el ser y la intuición intelectual que se eleva por encima del ser. En el saber hay pues un hyatus que se supera únicamente por la libertad mediante un saltus. De forma semejante al hyatus entre el conocer y el noúmeno kantiano, Fichte admite en la realidad una cierta dualidad entre el conocer y el ser en sí.

Fabro advierte que en lo que se refiere a esta dualidad, el filósofo alemán despliega en la Wissenschaftslehre "nova methodo” una postura más radical. En efecto, allí presenta la superación de la posición kantiana mediante la afirmación del primado absoluto de la voluntad y la asunción a un mismo tiempo de los fenómenos y de los noúmenos en el interior mismo de la conciencia. ${ }^{23}$ El querer puro (reine wollen) se muestra como la esencia última y profunda del espíritu. Todavía más, el querer puro se identifica con el propio ser. Al respecto Fabro destaca la siguiente aseveración de Fichte:

Yo no devengo sino que soy absoluto mediante el querer puro. En efecto, el querer puro determina toda mi esencia - mi ser (Wesen-Sein) -. Soy consecuentemente una esencia que quiere por toda la eternidad. Este puro querer es mi ser y mi ser es mi querer; ambos son una misma cosa. No hay nada más que añadir. Esto es lo que hemos llamado realidad (Wurzel $=$ raíz) originaria del Yo; efectivamente, solo un querer y el

${ }^{23}$ Cf. C. FABRO, "Breve discorso sulla libertà..., 273. 
querer puro puede devenir objeto inmediato de la conciencia. Por tanto, este puro querer ha de tener una realidad originaria. ${ }^{24}$

Ahora bien, señala el mismo Fichte, todo acto de conciencia se plantea como inclinación a un objeto, como tendencia a alguna cosa que está fuera del sujeto. Solo en función de esta relación es posible captar su realidad. No obstante ello, el querer puro (reine wollen) no tiene objeto alguno al cual referirse. Por consiguiente, es menester determinar el objeto para poder obrar en el mundo de los fenómenos. Tal determinación adviene mediante el sentimiento (Gefühl).

El Todo (das Ganze) de esta situación resulta la síntesis del querer y del ser. El querer es el fondo de la conciencia, el noúmeno que funda la actividad. El intuir sensible, por su parte, es aquello que proporciona la materia, el objeto que requiere el querer para poder determinarse. $^{25}$

Fabro no se detiene demasiado a examinar cómo el filósofo alemán desarrolla en su obra la forma de mediación del pensamiento entre el querer puro y el querer determinado, sino que rápidamente pasa a destacar una cita de importancia capital para advertir la flexión fichteana del ser a querer:

Mi verdadero ser es determinación del querer. Este es todo mi ser. Está comprendido en el tiempo y por ello yo devengo, aunque ya existiera antes. El todo es un ser determinado por un querer: este es mi estado total. ${ }^{26}$

\footnotetext{
${ }^{24}$ La cita de Fichte reclama, dada su importancia, una exposición más completa: «Ich werde nichts, sondern ich bin absolut durch den reinen Wollen. Durch diesen ist mein ganzes Wesen - Sein - bestimmt. Ich bin nur ein so wollendes Wesen für alle Ewigkeit. Dieses reine wollen ist mein Sein, und mein Sein ist mein wollen; beide sind eins und erschöpfen sich. Es läszt sich nichts hinzu noch davon tun. Dies nannten wir aber die ursprüngliche Realität (Wurzel) des Ich; denn nur ein Wollen und das reine wollen ist fähig, unmittelbares Objekt des Bewusztseins zu werden. Daher musz dieses reine wollen ursprüngliche Realität haben» (J. G. FICHTE, Wissenschaftslehre "nova methodo”, en J. G. FICHTE, Nachgelassene Schriften, H. Jakob, Berlín, 1937, Bd. 2, 482).

${ }^{25}$ Cf. C. FABRo, "La libertad en el pensamiento contemporáneo", tr. Enrique Benedicto, en Atlántida, vol. 4, n. 24, 1966, 14-15.

26 «Mein wahres Sein ist Bestimmtheit des Wollens. Dies ist mein ganzes Sein. Dies wird in der Zeit aufgefasst und dadurch werde ich, ob ich gleich schon vorher bin. Das Ganze ist ein durch ein wollend bestimmtes Sein, diez ist mein ganzes Zustand» (J. G. FICHTE, Wissenschaftslehre “nova methodo”..., 483).
} 
Para comprender bien este fundamental asunto, es menester tener presente que para Fichte debe admitirse además de la intuición sensible, también la intuición intelectual (intellektuelle Anschauung) que Kant en su filosofía negaba. ${ }^{27}$

Para Fichte la intuición sensible se relaciona con la particularidad y la exterioridad, esto es, con el darse inmediato de los contenidos sensoriales. Esta esfera constituye el Sein que el idealismo trascendental interpreta, de acuerdo con Kant, como posición empírica de algo en el espacio y en el tiempo.

La intuición intelectual, en cambio, no conduce a un ser sino a un obrar. ${ }^{28}$ Ella hace referencia a la libertad en acto, a la experiencia interna y no sensible del actuar del Sujeto como inmediación de presencia del querer puro y de su actuar. Kant no se refirió a ella más que con la expresión apercepción pura. Sin embargo, nota Fabro, con la fuerte proclamación del imperativo categórico mostró que el propio actuar de la libertad está en el centro mismo de la conciencia como objeto inmediato de la misma.

El idealismo trascendental, por lo tanto, se remonta al fondo y origen mismo de la actividad de la conciencia, a la voluntad pura como cualidad y condición (Zustand) completa del Yo.

\section{La confrontación fabriana con el idealismo trascendental de Fichte}

Fabro elogia en repetidas ocasiones el ímpetu especulativo con el que Fichte se dedica al problema de la libertad:

\footnotetext{
${ }^{27}$ «Al parecer, el punto de partida de esta decisiva doctrina de la intuición intelectual la tomó Fichte -y por su mediación Schelling y Hegel- de la doctrina de la sustancia de Spinoza. El paso del dogmatismo espinociano [sic] a la filosofía trascendental de la Wissenschaftslehre se realizó mediante la introducción del "Yo absoluto" desde la Grundlage der gesammeten Wissenschaftslehre de 1794» (C. FABRO, "La libertad en el pensamiento contemporáneo..., 16-17).

${ }^{28}$ Fichte explica esta cuestión con los siguientes términos: «Alles Sein ist ihr notwendig ein sinnliches, denn sie leitet den ganzen Begriff erst aus der Form der Sinnlichkeit ab, und man ist in ihr vor der Behauptung eines Bezieheungsmittels darauf vollkommen gesichert. Die intellektuele Anschauung, von welcher die Wissenschaftslehre redet, geht gar nicht auf ein Sein, sondern auf ein Handeln» (J. G. FICHTE, Zweite Einleitung in die Wissenschaftslehre, § 6, Medicus, III, 56.
} 
Toda la especulación de Fichte, en la intensa e incesante evolución de su pensamiento, no es más que una renovada reflexión sobre la originalidad de la libertad. ${ }^{29}$

Y en una de sus dispensas universitarias escribe:

Fichte es el "clásico de la libertad" y toda su actividad de hombre y de pensador en el sucederse de las Wissenschaftslehren es un continuo y jamás satisfecho empeñarse por este tema central. ${ }^{30}$

Una opinión semejante expresa aquí:

Las diversas y atormentadas Wissenschaftslehren, con las cuales [Fichte] ha colmado su singular actividad especulativa, no son en realidad más que diversas Freiheitslehren, es decir, intentos por descubrir el fondo y el fundamento de la libertad como el núcleo de la actividad espiritual. ${ }^{31}$

Sin ocultar la complacencia por la honda y extensa dedicación fichteana a la problemática de la libertad, Fabro hace explícito, a un tiempo, sus puntos de fundamental discordancia. Una de las principales características del pensamiento moderno, si no es quizá la más importante para el pensador italiano, es la fundación de la verdad en el horizonte del ser del hombre, de su conciencia y de su libertad. En esta dirección se plantean principios filosóficos que según los autores y las temáticas se combinan en ecuaciones cada vez más resolutivas: la verdad deviene interioridad, la interioridad deviene pensar y el pensar deviene finalmente autodeterminación, querer. ${ }^{32}$

En este despliegue de la filosofía moderna Fichte se erige como uno de sus más insignes actores. Efectivamente la absolutez del saber que presenta su doctrina no proviene

${ }^{29}$ «Tutta la speculazione di Fichte, nell’intensa e incessante evoluzione del suo pensiero, non è che una rinnovata riflessione sull'originalità della libertà» (C. FABRO, "Orizzontalità e verticalità nella dialettica della libertà”, en Riflessioni sulla libertà, 2 ed., Edivi, Segni, 2004, 20) Nota a pie de página.

30 «Fichte è il 'classico della libertà' e tutta la sua attività di uomo e di pensatore nel susseguirsi delle Wissenschaftslehren è un continuo e mai soddisfatto impegnarsi a questo tema centrale» (C. FABRO, Essere e Libertà, Dispense, Università di Perugia, Anno Accademico 1967-1968, 197) Nota a pie de página. Estas dispensas o cuardernillos universitarios son aun inéditos, aunque están en vías de su publicación por el Proggetto Culturale Cornelio Fabro de Italia que está a cargo de su Opere Complete.

31 «Le varie e tormentate Wissenschaftslehren, di cui ha riempieto la sua singolare attività speculativa, non sono in realtà che varie Freiheitslehren ossia tentativi di scoprire il fondo e il fondamento della libertà come il nocciolo dell'attività spirituale» (C. FABRO, "Breve discorso sulla libertà..., 268).

${ }^{32}$ Cf. C. FABRO, Essere e libertà..., 196-197. 
del saber sino que es un producto de la libertad absoluta. Esta libertad no tiene reglas ni leyes ajenas a sí misma, ${ }^{33}$ es la absoluta inmanencia o bien la absoluta autonomía del sujeto. $^{34}$

La fundación de estas fórmulas se remite a dos principios esenciales de su sistema. El primero anuncia la reducción del ser a la conciencia:

Todo ser, tanto del Yo como del No-Yo, es una determinada modificación de la conciencia y sin una conciencia no hay ningún ser. ${ }^{35}$

El segundo principio anuncia la reducción trascendental del ser a la libertad:

Ninguna naturaleza y ningún ser si no mediante la voluntad, los productos de la voluntad son el verdadero ser. ${ }^{36}$

Estos principios evidencian, en opinión del filósofo italiano, el giro especulativo de la modernidad con respecto al pensamiento clásico. El horizonte de la verdad, el status in quo de la verdad, no tiene más su comienzo (cominciamento) en el ser del mundo, en la presencia del ser del mundo, sino más bien en la presencia inmediata del Yo, en la presencia de la conciencia a sí misma como acto de libertad que se abre al infinito. ${ }^{37}$

En el idealismo fichteano la libertad, y más concretamente la autofundación de la libertad, ocupa el lugar central de la reflexión teorética. Este idealismo no atiende a la dialéctica de ser y libertad como en el realismo metafísico, sino más bien a la dialéctica de saber y libertad. Este último binomio dialéctico, según juzga Fabro, deja sin efecto tanto la trascendencia del ser cuanto la trascendencia misma de la libertad. ${ }^{38}$

La intuición intelectual (intellektuelle Anschauung) sobre la que Fichte se pronuncia no hace referencia al ser, sino a la identidad de saber (Wissen) y libertad (Freiheit) en cuyo término se encuentra el saber absoluto. Para Fichte, como para todo el idealismo metafísico

${ }^{33}$ Cf. J. G. FICHTE, Darstellung der Wissenschaftslehre aus dem Jahre 1801, § 11-12.

${ }^{34}$ Cf. C. FABRO, Essere e libertà..., 195-196.

35 «Alles Seyn, des Ich sowohl, als des Nicht-Ich, ist eine bestimmte Modification des Bewusstseyns; und ohne ein Bewusstseyn giebt es kein Seyn» (J. G. FICHTE, Grundlage des Naturrechts nach Principien der Wissenschaftslehre, Einleitung, Medicus, II, 6).

36 «Keine Natur und kein Sein ausser durch den Willen, die Freiheitsprodukte sind das rechte Sein» Citado por: C. FABRO, "Orizzontalità e verticalità..., 20.

${ }^{37}$ Cf. C. FABRO, "Orizzontalità e verticalità..., 20. También: Cf. C. FABRO, Essere e libertà..., 197.

${ }^{38}$ Cf. C. FABRO, "Breve discorso sulla libertà..., 270. 
en general, la actualidad de la conciencia no proviene de lo real que le viene dado, sino más bien de lo real que ella misma se da o bien que ella misma se hace presente en su reflexión sobre sí. ${ }^{39}$

Es verdad que Fichte admite, como se analizó en el apartado anterior, cierta dualidad en el saber, una separación entre el ser y la intuición que se supera con el salto de la libertad. Sin embargo, dice Fabro, esa dualidad o mejor dicho ese hyatus entre el ser en sí y el conocer «está destinado a estar y permanecer insuperable hasta en tanto la libertad sea interna al saber, es decir, [sea] una función del saber mismo», la cual, continúa el filósofo italiano «se identifica en Fichte, como se ha visto, con la intuición intelectual, esto es, con la autonomía que es espontaneidad del cogito». ${ }^{40}$

La doctrina de Fichte opera en opinión del filósofo italiano una construcción inmanente del real que se asienta en la no-contradicción de los términos que se hacen presentes a la razón, a saber, conciencia-autoconciencia, voluntad-inteligencia, fenómenonoúmeno, experiencia-saber. La identidad de estos conceptos se lleva a cabo metódicamente a través de la acentuación de la circularidad del Yo al interno de sí.

Ahora bien ¿cuál es según Fabro la conclusión de esta identificación de los opuestos? En breves palabras: la disolución radical del acto de elección, esto es, la pérdida de la libertad de elección (Wahlfreiheit), la cual Fichte, por su parte, identifica con la voluntad exterior. $^{41}$

Para Fichte el simple análisis del concepto de libertad supone la presencia del Yo y su concomitancia con el objeto, esto es, la concomitancia con la realidad que se representa gracias a la imaginación (Einbildungskraft). El Yo entonces, al ponerse a sí mismo elige con libertad entre las opuestas determinaciones de la realidad representada. Esta autoposición del Yo, según entiende Fichte, está bajo el poder del puro concepto. Frente a estas dos proposiciones Fabro muestra su discrepancia:

\footnotetext{
${ }^{39}$ Cf. C. FABRO, "Breve discorso sulla libertà..., 272.

40 «...è destinato ad essere e a rimanere insuperabile fin quando la libertà è interna al sapere ossia una funzione del sapere stesso e che s'identifica in Fichte, come si è visto, con l'intuizione intellettuale ossia con la autonomia ch'è la spontaneità del cogito» (C. FABRO, "Breve discorso sulla libertà..., 273).

${ }^{41}$ Cf. C. FABRO, "Dialettica della libertà..., 142. Este aspecto de la libertad de elección se encuentra una sola vez tratada, según el filósofo italiano, en la en la obra: Cf. J. G. FICHTE, Das System der Sittenlehre nach den Prinzipien der Wissenschaftslehre, Medicus, Bd. II, 473 ss, 553 ss.
} 
Es verdad que para poder elegir, es necesario antes disponer de distintas "posibilidades" - de elección - y por lo tanto de una realidad distinta del Yo en la cual se encuentren tales objetos: pero si esta realidad está puesta con y por el Yo que pone piensa - a sí mismo y si la libertad no es más que la fuerza que está bajo el poder del puro concepto, no se ve cómo el Yo que pone y que produce el mundo - mediante la trascendental Einbildungskraft - pueda distinguirse del mundo puesto [...]. Ni se ve qué cosa pueda seguir de acuerdo con la libertad si la libertad, la decisión libre, es hecha depender de la fuerza del puro concepto. ${ }^{42}$

La crítica se dirige específicamente a la identidad incomprensible ${ }^{43}$, según los términos mismos de Fabro, de pensar y querer:

Hasta en tanto el pensar sea la realidad del querer y lo absorba en sí, sin residuos, no habrá razón de poner un querer y tanto menos [de poner] el problema de la "elección libre" que supone una alternativa abierta que toca al sujeto cerrar o abrir mediante precisamente el acto personal de la elección el cual con esto cualifica las modalidades de la persona. ${ }^{44}$

Esta objeción no se limita únicamente al idealismo fichteano, sino también a toda forma de racionalismo que identifique facultades que se distinguen en la realidad:

El circulus conclusus de todo racionalismo, y tanto más del inmanentismo moderno, está en el unificar como un mismo acto de libertad dos funciones distintas cuales son la

\footnotetext{
${ }^{42}$ «È vero che per poter scegliere, bisogna prima disporre di varie 'possibilità' - di scelta - e quindi di una realtà distinta dall'Io nella quale si trovino tali oggetti: ma se questa realtà è posta con e dall'Io che pone pensa - se stesso e se la libertà non è che la forza che sta sotto il potere del puro concetto, non si vede come l'Io ponente e producente il mondo - mediante la trascendentale Einbildungskraft - si distingua dal mondo posto [...] Né si vede cosa possa seguire secondo libertà quando la libertà, la decisione libera, è fatta dipendere dalla forza del puro concetto» (C. FABRO, "Dialettica della libertà..., 144) Cursiva del autor.

${ }^{43}$ «....il pensare e il volere sono sfumati e svaniti in un'identità incomprensibili» (C. FABRO, "Breve discorso sulla libertà..., 275)

${ }_{44}^{4}$ «Fin quando il pensare è la realtà del volere e l'assorbe in sé, senza residui, non c'è più ragione di porre un volere e tanto meno il problema della 'scelta libera' che suppone un'alternativa aperta che tocca al soggetto chiudere o aprire mediante appunto l'atto personale della scelta il quale con questo qualifica le modalità della persona» (C. FABRO, "Dialettica della libertà..., 144).
} 
presentación del objeto y la decisión o bien la elección concreta de un objeto en vista de la consecución de un fin. ${ }^{45}$

Para el filósofo italiano ambos órdenes no deben confundirse ni fusionarse sino que deben permanecer en relación dialéctica: la presentación del objeto atañe a la inteligencia, la consecución del fin compete a la voluntad. El problema de fondo del idealismo, que Fabro identifica aquí con el inmanentismo, está ante todo en asentar la unidad de los diversos que termina por deducir lo concreto de lo abstracto, lo real de lo formal, los muchos de lo uno, y en fin, la existencia de la esencia. ${ }^{46}$

No está de más aclarar nuevamente que a la identidad dinámica de pensar y querer, inteligencia y voluntad, subyace la identidad de ser y pensamiento que Fabro reprueba enérgicamente. Fichte afirma que el ser racional no puede verdaderamente pensar una acción como real si no es admitiendo algo fuera del sujeto que realiza la acción. ${ }^{47}$ Ahora bien, se pregunta Fabro ¿Cómo es posible pensar esa acción como real si toda acción pensada es una acción solamente en el pensamiento, es decir, pura representación de un mundo por parte del sujeto? Asimismo ¿Cómo es posible representarse esa realidad como objeto de elección por parte del sujeto si precisamente esa realidad es inmanente al Yo? ${ }^{48}$

Fichte reconoce que la actividad del Yo pensante-queriente tiene una actividad propiamente ideal, un movimiento subjetivo. Pero a la vez añade, como explicación de su Wahlfreiheit, que ese movimiento implica lo objetivo. La realidad objetiva es un No-Yo, es decir, algo (etwas) que está fuera del sujeto. Ese algo, sin embargo, es también actividad del sujeto, posición del No-Yo por parte del Yo.

Fabro considera que este desarrollo de la liberad es ambiguo y contradictorio y no hace más que eliminar el verdadero momento existencial de la moralidad, esto es, la posibilidad de elección de la persona:

\footnotetext{
45 «Il circulus conclusus di ogni razionalismo, e tanto più dell'immanentismo moderno, è nell'unificare come uno stesso atto di libertà due funzioni diverse quali sono la presentazione dell'oggetto e la decisione ovvero la scelta concreta di un oggetto in vista del conseguimento di un fine» (C. FABRO, "Breve discorso sulla libertà..., 274) Cursiva del autor.

${ }^{46}$ Cf. C. FABRO, "Dialettica della libertà..., 137-138.

47 «Das Vernunftwesen kann keine Handlung als wirklich denken, ohne etwas ausser sich anzunehmen, worauf diese Handlung gehe» (J. G. FICHTE, Das System der Sittenlehre..., 475.

${ }^{48}$ Cf. C. FABRO, "Dialettica della libertà..., 144.
} 
En sustancia el acto de querer [en el pensamiento de Fichte] no arriba jamás a concretarse en un acto de "elección" cual se exige para la "apropiación concreta del propio fin" que cada uno se prefija. ${ }^{49}$

Un último aspecto a tener en cuenta en esta discusión es la disolución, según el parecer del filósofo italiano, de los yoes singulares en el Yo universal. Para el idealismo de Fichte el Yo no es otra cosa más que un obrar sí mismo. Dice Fabro: «Se trata de un obrar puro como pura presencia a la conciencia que es el Yo como agente, no como sustrato o cosa en sí o sustancia». ${ }^{50}$ Esta concepción tiene como consecuencia inmediata la «eliminación de la consistencia ontológica del singular - como persona o sea - como objeto en sí y centro operativo» ${ }^{51}$.

El trascendental fichteano parece excluir de principio la individualidad, pues toda multiplicidad de los yoes (Iche), esto es, toda multiplicidad de los individuos-personas, se pone en el plano de la aparición (Erscheinung). Los individuos se hacen co-presentes al Yo-Uno, se recogen en el Yo-Uno que, constituido en forma, es su regla y norma universal. La acción (Wirkung) del hombre, su libertad, aparece como un producto de la naturaleza material. El acto de querer, elegir, decidir, no recae en la autointuición del Yo individual, sino en el Uno, en la intuición de la egoidad (Ichheit) por la que todo particular, como modo de éste, deviene algo objetivo y universal.

El Yo trascendental, examina Fabro, en un primer momento se exterioriza, se dispersa en lo múltiple, en los muchos yoes que son conscientes de su libertad. Luego se retoma en la unidad como resultado invisible e inconsciente de sí, como luz impersonal que no se ve a sí misma sino que se muestra en aquello que ilumina. ${ }^{52}$

La conclusión de Fabro nuevamente retoma el punto esencial de la crítica anterior, la disolución de la libertad de elección:

\footnotetext{
49 «In sostanza quindi l'atto del volere non arriva mai a concretarsi in un atto di 'scelta' quale si esige per la 'appropriazione concreta del proprio fine', che ciascuno si prefigge» (C. FABRO, "Dialettica della libertà..., $145)$.

${ }^{50}$ «Si tratta di un puro agire puro come pura presenza alla coscienza ch'è l'Io come agente, non come sostrato o cosa in sé o sostanza» (C. FABRO, "Dialettica della libertà..., 133).

51 «...eliminazione della consistenza ontologica del singolo - come persona cioè - come oggetto in sé e centro operativo» (C. FABRO, "Breve discorso sulla libertà..., 277).

${ }^{52}$ C. FABRO, "Breve discorso sulla libertà..., 278-279.
} 
Fichte, como todo el idealismo, no ve aun que el núcleo de la libertad es el acto de elección, es decir, la decisión de la libertad de elección o sea la libertad como dominio del acto y del objeto sobre el fundamento de la elección radical que es el Bien absoluto. Él sólo puede quitar toda dispersión de la indiferencia a la cual está condenada la conciencia entendida como negatividad. Toda la actividad especulativa de Fichte no ha sido otra más que buscar el sentido y el fundamento de la libertad y por tanto el suyo ha sido el discurso más largo sobre la libertad en toda la historia del pensamiento y sin embargo esta filosofía entera es también - y propiamente por esto - el discurso más breve sobre la esencia de la libertad. ${ }^{53}$

La crítica, como puede observarse, es verdaderamente severa.

\section{Consideraciones finales}

Fabro sostiene que la obra fichteana no pretende dejar sin efecto el pensamiento kantiano, sino que más bien quiere dar un paso "dentro" de la misma, superando desde el mismo ámbito práctico sobre el que éste se pronuncia, aquella serie de dualismos que en su crítica resultan irresolubles. En este sentido Fichte profundiza el inicio cartesiano que perfecciona y sistematiza la filosofía kantiana, concediendo de igual modo que sus antecesores, aunque con características del todo peculiares según lo ya descrito, la primacía de la conciencia por sobre el ser.

Según estima el filósofo italiano esta primacía metafísica de la conciencia designa el núcleo del pensamiento moderno y su más profundo error. El ser no es lo fundado, no es un acto derivado, ni es consecuencia de la actividad del Yo, sino que es el acto de todos los actos, el acto actuante, el acto fundante, inderivable y originario que antecede a la conciencia, el principio determinativo esencial gracias al cual se hace posible todo despliegue del Yo, toda aprehensión del pensamiento y toda inclinación de la voluntad.

\footnotetext{
53 «Fichte, come tutto l'idealismo, non vede ancora che il nocciolo della libertà è l'atto di scelta cioè la decisione della libertà di scelta, cioè la libertà come dominio dell'atto e dell'oggetto sul fondamento della scelta radicale ch'è il Bene assoluto. Egli solo può togliere ogni dispersione dell'indifferenza a cui è condannata la coscienza intesa come negatività. Tutta l'attività speculativa di Fichte non è stato altro che un cercare il senso ed il fondamento della libertà e pertanto il suo è stato il discorso più lungo sulla libertà in tutta la storia del pensiero. Eppure questa filosofia intera è anche - e proprio per questo - il discorso più breve sull'essenza della libertà» (C. FABRO, "Breve discorso sulla libertà..., 279).
} 
La inmanencia radical del ser a la conciencia que proclama el idealismo en su identidad absoluta, es en última instancia disolución radical del ser de conciencia y disolución radical del movimiento de la conciencia hacia el ser. La conclusión de esta afirmación es tan grave en el plano metafísico como en aquel existencial. Sin distinción de órdenes y sin relación dialéctica de lo diverso no es posible el dinamismo del espíritu que se mueve entre los opuestos. La libertad queda así relegada al análisis puramente formal, esto es, a una consideración meramente abstracta y estática que no atiende a su verdadero ser, es decir, a la concreción, a la singularidad y al dinamismo de la persona.

La libertad es el acto del Yo, la autodeterminación, autoposición de la conciencia y en esto Fabro esta completamente de acuerdo con Fichte. Esta causación de sí es afirmación absoluta del Yo, pero no es afirmación del Yo Absoluto Universal, sino del Yo absoluto individual que es cada persona, cada espíritu, cada sujeto. Aquí está la novedad del pensamiento fabriano, el hombre es un ser ontológicamente finito dependiente de un otro que él (Dios), existencialmente infinito y absoluto por su libertad.

Esta libertad, esta absolutez de la libertad se revela en el acto y solamente en el acto, acto que tiene por nombre "elección” (scelta). Aquí, y no en otro lugar, radica la esencia de la libertad para Cornelio Fabro, y solo a partir de ella su crítica y su aprobación, su acusación y su admiración por Fichte cobra verdadero sentido.

La trascendencia del Ser por esencia, la creación y causalidad divina, la indigencia radical de los entes - tanto en el ser cuanto en el obrar- y la composición y división ontológica de todas las creaturas, son algunos de los más importantes supuestos metafísicos con los que Fabro aborda la lectura fichteana, los cuales, precisamente por esa misma lectura, se ven redimensionados y redefinidos en un plano existencial en el que el autor italiano concibe la infinitud del espíritu, la simplicidad del ser y la inmanencia total y perfecta de la libertad.

La compatibilidad o incompatibilidad, coherencia o no, de los planos especulativos que se presentan en la obra de Fabro merecen un tratamiento aparte; en este lugar solo se deja abierta la cuestión para posibles y posteriores discusiones de la problemática. 